\title{
APORTE DE CARBONO SOLÚVEL PELO SISTEMA RADICULAR DE ARROZ E SUA INFLUÊNCIA NOS TEORES DE SUBSTÂNCIAS HÚMICAS DE UM LATOSSOLO VERMELHO-AMARELO ${ }^{(1)}$
}

\author{
Erika Polverari Farias ${ }^{(2)}$, Everaldo Zonta ${ }^{(3)}$, Luciano Pasqualoto \\ Canellas $^{(4)}$ \& Gabriel de Araujo Santos ${ }^{(5)}$
}

\begin{abstract}
RESUMO
O objetivo deste trabalho foi quantificar a contribuição da deposição de Corgânico solúvel pelo sistema radicular de arroz e a evolução de $\mathrm{CO}_{2}$, durante 64 dias de incubação, em amostras de um Latossolo Vermelho-Amarelo com adição de glicose e de raízes de arroz coletadas em diversos estádios de crescimento da planta (aos 40, 60, 80, 100, 120 e 140 dias da semeadura). Foi realizado o fracionamento da matéria orgânica humificada para avaliar o efeito da adição de sistema radicular na composição do húmus do solo. A rizodeposição de C-orgânico via exsudatos e, ou, decomposição de tecidos mortos mostrou-se correlacionada com o estádio de desenvolvimento da cultura. A rizodeposição total foi estimada em valores ao redor de $90 \mathrm{~g} \mathrm{~m}^{-2}$ de $\mathrm{C}$ por ciclo da planta. A adição de $\mathrm{C}$ via raízes às amostras de solo promoveu intensa mineralização da matéria orgânica preexistente no solo, principalmente nos primeiros dias de incubação, e aumentou o teor de $\mathrm{C}$ na fração ácidos fúlvicos do húmus, no final do experimento.
\end{abstract}

Termos de indexação: ácidos fúlvicos, ácidos húmicos, huminas, Oryza sativa, efeito priming.

\footnotetext{
(1) Parte da Tese de Mestrado do primeiro autor, apresentada à Universidade Federal Rural do Rio de Janeiro - UFRRJ. Recebido para publicação em agosto de 2002 e aprovado em outubro de 2005.

(2) Engenheira-Agrônoma do Fundo Brasileiro para a Biodiversidade - FUNBIO. Largo do Ibam, 01/6 andar. Humaitá, CEP 22271070. Rio de Janeiro (RJ).

(3) Professor Adjunto do Departamento de Solos, Universidade Federal Rural do Rio de Janeiro - UFRRJ. Br 465, km 7, CEP 23851970 Seropédica (RJ). E-mail: ezonta@ufrrj.br

(4) Professor Associado do Centro de Ciências e Tecnologias Agropecuárias, Universidade Estadua do Norte Fluminense - UENF. Laboratório de Solos. Av. Alberto Lamego 2000, CEP 28015-620 Campos (RJ). Bolsista do CNPq. E-mail: canellas@uenf.br

(5) Professor Titular do Departamento de Solos, UFRRJ. Bolsista do CNPq. E-mail: gasantos@ufrrj.br
} 


\title{
SUMMARY: INPUT OF DISSOLVED CARBON AND ITS INFLUENCE ON HUMIC SUBSTANCES CONTENT IN AN OXISOL
}

\begin{abstract}
The aim of this study was to quantify the contribution of soluble organic- $C$ deposition by rice root system and the $\mathrm{CO}_{2}$ evolution during 64 days in an Oxisol samples treated with glucose, and rice roots collected at different plant growth stages (40,60, 80, 100, 120 and 140 days after sowing). Thereafter, organic matter was fractionated to evaluate the effect of the addition of a root system on the soil humus composition. It was possible to observe the intense rhizodeposition of organic $C$ by exudation or by decomposition of dead tissues. Organic $C$ deposition via rhizodeposition was correlated with the plant development stages. Total rhizodeposition was estimated to be around $90 \mathrm{~g} \mathrm{~m}^{-2} \mathrm{C}$ per plant cycle. The addition of organic C into soil samples via roots promoted intense mineralization of the native soil organic matter, particularly in the beginning of the incubation period, and eventually enhanced the fulvic acids concentration by the end of the experiment.
\end{abstract}

Index-terms: humic acids, fulvic acids, humans, Oryza sativa, priming effect.

\section{INTRODUÇÃO}

O húmus do solo é formado por compostos orgânicos macromoleculares, obtidos da transformação de restos de plantas, animais e microrganismos, e não apresenta semelhança morfológica com o material que lhe deu origem. Os ácidos húmicos (AH), os ácidos fúlvicos (AF) e as huminas $(\mathrm{H})$, classificados com base na sua solubilidade em meio aquoso ácido ou alcalino, constituem a maior parte do húmus do solo, sendo classificados como substâncias húmicas. Já a menor parte do húmus é formada pelas substâncias não-húmicas, ou seja, substâncias com propriedades químicas definidas, tais como: ácidos orgânicos de baixo peso molecular, polissacarídeos, aminoácidos, ceras e graxas (Camargo et al., 1999).

A dinâmica da formação desse sistema complexo de compostos orgânicos é determinada, para um mesmo clima, relevo e material de origem, pela qualidade da fonte primária de $\mathrm{C}$ que é adicionada ao solo. Os indicadores de qualidade dos resíduos animais e vegetais mais utilizados são a relação C/ $\mathrm{N}$ e os teores de ligninas que dirigem as reações de mineralização ou de imobilização da matéria orgânica.

Stevenson (1994) postulou, em seu modelo de humificação, que os compostos orgânicos liberados durante uma primeira fase rápida de biodegradação dos resíduos orgânicos no solo são transformados, química ou biologicamente até compostos relativamente mais resistentes à degradação biológica que interagem intimamente com a matriz mineral (Orlov et al., 2004).

Existem vários modelos para descrever a estrutura das substâncias húmicas resultantes do processo de humificação. De acordo com Stevenson (1994) e Camargo et al. (1999), as substâncias húmicas no solo podem ser consideradas como macromoléculas com comportamento de um polieletrólito de ácido fraco, ou seja, uma reunião íntima de várias unidades moleculares que apresentam polifuncionalidade e carga predominante negativa. A conformação do polieletrólito macromolecular varia, em solução, de acordo com o $\mathrm{pH}$ e com a força iônica do meio (I). Em solução, unidades moleculares provenientes da decomposição parcial dos resíduos, poderiam, de acordo com Wershaw (1993), em contato com a fração mineral, resultar na formação de estruturas micelares com uma parte polar voltada para o exterior e outra parte, apolar ou hidrofóbica, voltada para o interior da micela. Esse caráter pseudomicelar foi observado por Engbretson \& Wandruszka (1994) por meio da queda de fluorescência de uma sonda imersa numa solução que continha ácidos húmicos. A adição de cátion divalente aumentou consideravelmente o caráter hidrofóbico dessa solução, sendo interpretado pelos autores como a evidência de formação de estruturas pseudomicelares formadas a partir de pontes com íons metálicos.

Verifica-se que a formação de micelas ou pseudomicelas requer, necessariamente, que a concentração de substância anfifílica em solução (com caráter anfótero) seja maior que a concentração micelar crítica (Swift, 1999), o que é pouco provável para o caso de substâncias húmicas em ambientes tropicais altamente intemperizados.

Uma evolução desse modelo foi sugerido por Conte \& Piccolo (1999) que postularam um arranjamento pseudomacromolecular para as substâncias húmicas, ou seja, pequenas unidades moleculares formariam agregados húmicos unidos por forças fracas predominantemente hidrofóbicas. Dessa forma, as substâncias húmicas apresentariam uma massa molecular só aparentemente elevada. Observou-se, entretanto, quando da alteração das condições da solução (variações do pH), que as forças responsáveis pela interação entre os agregados húmicos poderiam ser rompidas e liberadas 
pequenas unidades moleculares de substâncias húmicas com menor distribuição de massa molecular. Essa concepção foi fortemente criticada por Swift (1999), que considerou o modelo de arranjamento supramolecular como um produto do artefato produzido pela interação da solução de substâncias húmicas com o gel de sephadex, utilizado no experimento de Conte \& Piccolo (1999), com vistas em obter a distribuição de massa dos agregados moleculares com a variação de $\mathrm{pH}$ da solução de eluição. Entretando, os resultados obtidos por Conte \& Piccolo (1999) não foram contestados experimentalmente, e Façanha et al. (2002) reproduziram qualitativamente a mudança na distribuição de massa de uma solução de ácidos húmicos na presença de exsudados de raízes de plântulas de milho e de café.

Apesar do seu papel ambiental e agrícola crítico, pouco se conhece a respeito dos processos de transformação dos resíduos orgânicos em húmus do solo (Zech et al., 1997) e, menos ainda, do efeito do sistema radicular na distribuição e composição do húmus do solo (Kogel-Knaber, 2002). Por estar intimamente em contato com a fração mineral do solo e sofrer as reações de decomposição/ transformação num ambiente com menor pressão de $\mathrm{O}_{2}$, sugere-se que o aporte de $\mathrm{C}$ através do sistema radicular promova a formação de compostos insolúveis, as huminas (Ortega, 1982).

A alocação de C orgânico (C-org) no solo a partir de sistemas radiculares foi estudada por de Vogt et al. (1986), Raich \& Nadelhoffer (1989), Beudert et al. (1989) e Preston (1992), considerando sistemas florestais. Gill \& Jackson (2000), analisando os dados disponíveis sobre taxas de ciclagem de raízes em diversos sistemas de produção, postularam valores anuais de aproximadamente $10 \%$ da massa de raízes para espécies arbóreas e de $53 \%$ para raízes finas de gramíneas. Apesar de rapidamente consumido pelos microrganismos, o que dificulta a determinação, Kuzyalov \& Domanski (2000) estimaram o conteúdo de $\mathrm{C}$ exsudado pelo sistema radicular de trigo entre valores de 0,30 e $0,48 \mathrm{~g} \mathrm{~m}^{-2}$ ano $^{-1}$ de C, próximos aos obtidos por Bronson et al. (1998).

Esse trabalho teve por objetivo avaliar a contribuição potencial da rizodeposição de $\mathrm{C}$ solúvel numa solução pelo sistema radicular do arroz e verificar o efeito do aporte de $\mathrm{C}$ através do sistema radicular na evolução de $\mathrm{CO}_{2}$ e na composição do húmus de um Latossolo Vermelho-Amarelo.

\section{MATERIAL E MÉTODOS}

Dosagem do Carbono orgânico exsudado pelas raízes cultivadas em solução nutritiva Plântulas de arroz (Oryza sativa L.) do cultivar
IAC 4440 , obtidas a partir de sementes provenientes do banco de germoplasma do Centro Nacional de Pesquisa de Arroz e Feijão (Embrapa-CNPAF), foram transferidas para vasos (duas plantas/vaso) 15 dias após a semeadura (DAS), utilizando metade da concentração da solução nutritiva de Furlani \& Furlani (1988), por cinco dias. Aos 20 DAS, foi usada a concentração total da solução nutritiva e, aos 80 DAS, as plantas foram transferidas para vasos maiores $(6,3 \mathrm{~L})$. A solução nutritiva foi trocada a cada 20 dias até à colheita das plantas (140 DAS). Foram efetuadas seis coletas das plantas e da solução com intervalos de 40 dias, com quatro repetições, num delineamento inteiramente casualizado. Alíquotas obtidas da solução nutritiva foram centrifugadas a $3.000 \mathrm{x} \mathrm{g}$, obtendo-se uma fração solúvel (leve) e uma fração depositada (pesada). O C total, na fração leve e no material presente na solução nutritiva, foi determinado pelo método proposto por Walkley (1947).

Evolução de $\mathrm{CO}_{2}$ em horizonte superficial de um Latossolo Vermelho-Amarelo incubado com raízes de arroz - As principais características do horizonte superficial de um Latossolo VermelhoAmarelo (0-15 cm), coletado no Município de Barra do Piraí, Rio de Janeiro, Brasil, utilizado no experimento são: $\mathrm{pH}_{\mathrm{H}_{2} \mathrm{O}}=4,7 ; \mathrm{Ca}^{2+}=20 \mathrm{mmol}_{\mathrm{c}} \mathrm{dm}^{-3}$; $\mathrm{Mg}^{2+}=8 \mathrm{mmol}_{\mathrm{c}} \mathrm{dm}^{-3} ; \mathrm{K}^{+}=3,1 \mathrm{mmol}_{\mathrm{c}} \mathrm{dm}^{-3}$; $\mathrm{Al}^{3+}=20 \mathrm{mmol}_{\mathrm{c}} \mathrm{dm}^{-3} ; \mathrm{C}=19,8 \mathrm{~g} \mathrm{~kg}^{-1} ; \mathrm{N}=2,0 \mathrm{~g} \mathrm{~kg}^{-1}$; relação $\mathrm{C} / \mathrm{N}=10 ; \mathrm{P}=7 \mathrm{mg} \mathrm{dm}^{-3}$; areia $=510 \mathrm{~g} \mathrm{~kg}^{-1}$; silte $=210 \mathrm{~g} \mathrm{~kg}^{-1} ;$ argila $=280 \mathrm{~g} \mathrm{~kg}^{-1}$.

Para obter a curva de respiração do solo, adicionou-se às amostras de solo o equivalente a $20 \%$ do Corg preexistente no solo, utilizando uma massa de raízes de arroz coletadas aos 20, 40, 60, 80, 100 e 120 DAS do experimento anterior. Foram ainda obtidos um controle sem adição de $\mathrm{C}$, um controle com a adição da mesma dose equivalente da palha seca da parte aérea de arroz nos diferentes estádios de crescimento e um controle com adição de glicose (P.A.), fonte de $\mathrm{C}_{\text {org }}$ prontamente disponível. O sistema de incubação foi montado num delineamento experimental inteiramente casualizado, com quatro repetições, em potes vedados de $1,7 \mathrm{~L}$ com $100 \mathrm{~g}$ de solo + os tratamentos misturados e o $\mathrm{CO}_{2}$ evoluído captado por sonda de $\mathrm{NaOH} 1 \mathrm{~mol} \mathrm{~L}^{-1}$ imersa no pote. $\mathrm{O}$ teor de $\mathrm{C}_{\text {org }}$ capturado foi dosado diariamente, durante 64 dias, por titulação com $\mathrm{HCl}$ $2 \mathrm{~mol} \mathrm{~L}^{-1}$ do sobrenadante proveniente do precipitado formado pela adição de $\mathrm{BaCl}_{2} 3 \mathrm{~mol} \mathrm{~L}^{-1}$ (Santos \& Camargo, 1999).

Composição do húmus em amostras do horizonte Ap do Latossolo Vermelho-Amarelo incubado com raízes de arroz - Após o período experimental de 90 dias, as amostras de solos do experimento anterior foram submetidas ao fracionamento da matéria orgânica de acordo com o método de Belchikova-Kononova, descrito em Guerra \& Santos (1999). De forma resumida, uma 
amostra de $10 \mathrm{~g}$ de solos é submetida ao tratamento prévio com $\mathrm{H}_{2} \mathrm{PO}_{3} 2 \mathrm{~mol} \mathrm{~L}^{-1}$ (1:10, v/v) separando por densidade a fração restos vegetais (RV) e solubilizando a fração ácidos fúlvicos livres (AFL). Após sucessivas lavagens, a amostra de solo foi submetida à extração alcalina das substâncias húmicas pela mistura de solventes $\mathrm{NaOH}+\mathrm{Na}_{4} \mathrm{P}_{2} \mathrm{O}_{7}$ $0,1 \mathrm{~mol} \mathrm{~L}^{-1}(1: 10, \mathrm{v} / \mathrm{v})$ por $16 \mathrm{~h}$, enquanto o sobrenadante foi separado por centrifugação. A separação da fração ácidos húmicos $(\mathrm{AH})$ foi obtida pela acidificação do extrato alcalino até $\mathrm{pH}$ 1,0 com $\mathrm{H}_{2} \mathrm{SO}_{4}$, concentrado, seguido de resfriamento e centrifugação. A fração solúvel, após a acidificação do extrato alcalino, foi considerada como a fração ácidos fúlvicos (AF), e a fração residual não extraída do solo, como fração humina $(\mathrm{H})$. A dosagem de $\mathrm{C}$ em cada uma das frações foi efetuada por dicromatometria com calor externo e titulação por sulfato ferroso amoniacal $0,2 \mathrm{~mol} \mathrm{~L}^{-1}$.

\section{RESULTADOS E DISCUSSÃO}

A liberação de C via exsudado e de tecidos mortos em solução nas várias etapas do ciclo de desenvolvimento do arroz encontra-se no quadro 1. $\mathrm{O}$ período exponencial de crescimento da planta correspondeu ao maior conteúdo de $\mathrm{C}$ liberado em solução entre os 60 e 80 DAP. Após esse período, ocorreu menor liberação de $\mathrm{C}$ possivelmente em virtude da formação do dreno reprodutivo promovido pelo fluxo mais intenso de carboidratos necessário ao desenvolvimento das panículas. Nos estádios finais de desenvolvimento, o $\mathrm{C}$ encontrado em solução deveu-se, provavelmente, à decomposição dos tecidos radiculares mortos, uma vez que a maior parte do sistema radicular já não estava mais fisiologicamente ativo.

A partir dos dados de produção de massa seca de raízes (Quadro 1), foi possível estimar atematicamente a contribuição do sistema radicular na ordem de $90 \mathrm{~g} \mathrm{~m}^{-2}$ de $\mathrm{C}$ durante o ciclo da cultura de arroz, valor bastante significativo de $\mathrm{C}$ solúvel prontamente disponível para a atividade microbiana. A contribuição total de C-org ao solo via sistema radicular de gramíneas foi estimada por Gerzabek et al. (1997), como algo entre 30 e $50 \mathrm{~g} \mathrm{~m}^{-2} \mathrm{ano}^{-1}$ de $\mathrm{C}$, níveis abaixo dos obtidos nesse experimento; contudo, devem-se levar em consideração as condições ótimas de cultivo em casa de vegetação.

A evolução do $\mathrm{CO}_{2}$ acumulado durante a decomposição do sistema radicular nos diferentes estádios de desenvolvimento do arroz, quando incorporados às amostras do horizonte superficial do Latossolo Vermelho-Amarelo, é mostrada na figura 1a. Com a adição de glicose, fonte de $\mathrm{C}$ orgânico prontamente disponível, verificou-se o máximo de evolução de $\mathrm{CO}_{2}$, cerca de oito vezes superior ao da testemunha. Esse fato já foi relatado anteriormente e é conhecido como efeito "priming", em que a estimulação da atividade microbiana pela adição de resíduos orgânicos favorece muito a aceleração da decomposição da matéria orgânica do solo (Kuzyakov et al., 2000). O mesmo efeito, porém em menor intensidade, foi verificado com a incorporação de raízes ao solo. A natureza mais recalcitrante da fonte de matéria orgânica (maior relação $\mathrm{C} / \mathrm{N}$ ) e o menor conteúdo de C-prontamente oxidável promoveram a atividade microbiana num patamar menos elevado. A dinâmica da evolução do $\mathrm{CO}_{2}$ no tempo de incubação foi similar para todos os tratamentos (Figura 1b). Nas primeiras 48 h, houve o pico máximo de evolução de $\mathrm{CO}_{2}$ com um novo repique aparecendo em torno dos 10 dias de incubação, porém de intensidade bem menor. Num primeiro momento, constatou-se o forte estímulo na respiração microbiana pela adição de compostos solúveis (Luna-Guido et al., 2001) presentes no tecido vegetal e, numa segunda etapa, a evolução ecológica da biomassa e ataque de outros substratos (Oliveira, 1990). Em seguida, notou-se o decréscimo

Quadro 1. Carbono orgânico total (C total), C orgânico no sobrenadante (C leve) e no depositado (C pesado) liberado de acordo com dias após o plantio (DAP) de arroz após centrifugação da solução nutritiva

\begin{tabular}{|c|c|c|c|c|c|c|c|}
\hline DAS & $\mathrm{C}_{\text {total }}$ & $C_{\text {leve }}$ & $\mathbf{C}_{\text {pesado }}$ & $\begin{array}{c}\text { Matéria seca } \\
\text { acumulada nas raízes }\end{array}$ & $\mathrm{C} / \mathrm{N}$ & Teor de Lignina & Lignina/N \\
\hline & 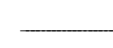 & $\mathrm{kg}^{-1}$ raíze & - & g planta-1 & & $\mathrm{g} \mathrm{kg}^{-1}$ matéria seca & \\
\hline 40 & nd & nd & nd & 0,6 & 27 & nd & - \\
\hline 60 & $4,5 \mathrm{~A}$ & $2,2 \mathrm{~A}$ & $2,5 \mathrm{~A}$ & 2,8 & 48 & 71 & 5 \\
\hline 80 & $4,6 \mathrm{~A}$ & $1,7 \mathrm{AB}$ & $1,1 \mathrm{~B}$ & 5,5 & 40 & 82 & 9 \\
\hline 100 & $2,5 \mathrm{~B}$ & $0,8 \mathrm{C}$ & $0,8 \mathrm{~B}$ & 8,6 & 40 & 63 & 10 \\
\hline 120 & $4,4 \mathrm{~A}$ & $1,8 \mathrm{AB}$ & $1,1 \mathrm{~B}$ & 9,6 & 48 & 62 & 7 \\
\hline 140 & $2,8 \mathrm{AB}$ & $1,2 \mathrm{BC}$ & $1,4 \mathrm{~B}$ & 10,4 & 50 & 34 & 4 \\
\hline
\end{tabular}

Médias seguidas de letras maiúsculas iguais, nas colunas, não são estatisticamente diferentes entre si pelo teste de Tukey ( $\mathrm{p}<0,05)$. nd: não determinado. 

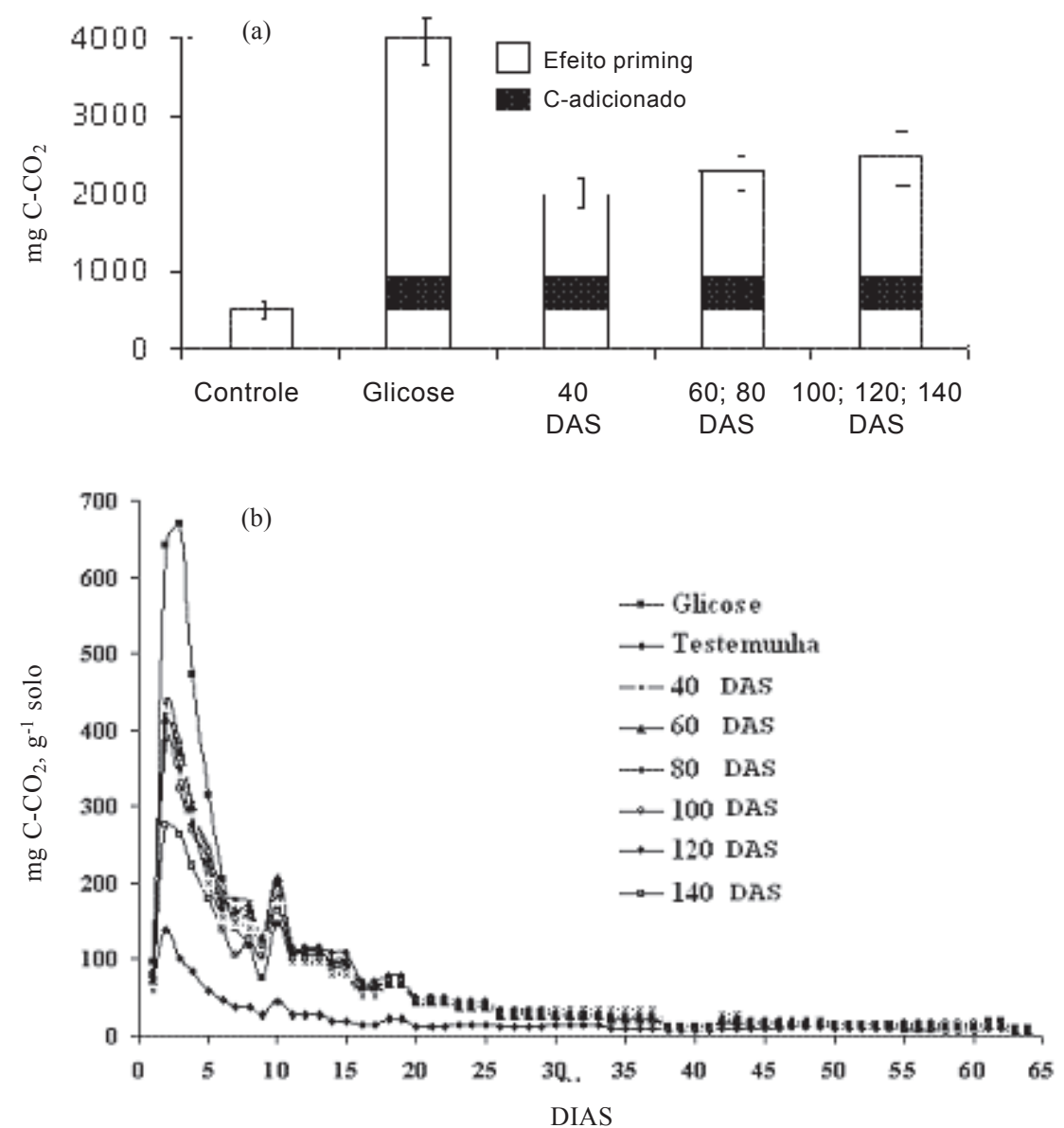

Figura 1. Acúmulo de $\mathrm{CO}_{2}$ durante todo o período de incubação (a) e evolução diária de $\mathrm{CO}_{2}$ (b) nas amostras sem adição de $\mathrm{C}$ (controle) e com adição de glicose e de raízes de arroz aos 40, 60, 80, 100, 120 e 140 dias da semeadura (DAS).

da evolução de $\mathrm{CO}_{2}$ com o tempo, até à estabilização da respiração do solo por volta dos 30 dias de incubação.

O fracionamento da matéria orgânica humificada no solo, após 90 dias de incubação com as raízes em diferentes estádios de desenvolvimento, encontrase no quadro 2. Nas amostras de solo com adição de C-org, através de glicose, foi verificado um acréscimo de 65 \% no conteúdo de $\mathrm{C}$ na fração humina, seguido de acréscimos menores nas frações ácidos fúlvicos (35\%) e ácidos fúlvicos livres (18\%) em relação à amostra-testemunha. A adição de $\mathrm{C}$ por meio de raízes alterou a dinâmica de transformação do $\mathrm{C}$ humificado. Notou-se um acréscimo de até $335 \%$ na fração ácidos fúlvicos nas amostras incubadas com raízes coletadas aos 40 DAS. À medida que aumentou a relação $\mathrm{C} / \mathrm{N}$, os acréscimos obtidos na fração ácidos fúlvicos diminuíram para 200, 160 e $105 \%$, aos 60, 80 e 100 DAS, respectivamente. Curiosamente, nos estádios finais de crescimento, 120 e 140 DAS, foi observado um novo aumento de 205 e 160 \% na fração ácidos fúlvicos, respectivamente. É possível que esse novo incremento esteja relacionado com a maior decomposição do sistema radicular. Os valores de $\mathrm{C}_{\text {org }}$ da fração humina aumentaram em cerca de $30 \%$ com a adição de raízes, exceto nas amostras incubadas com raízes coletadas aos 60 DAS, quando os acréscimos foram da ordem de $105 \%$. A adição de $\mathrm{C}$ não alterou os valores de conteúdo de $\mathrm{C}$ na fração ácidos húmicos.

A evolução da matéria orgânica do solo, segundo Santos \& Camargo (1999), compreende as transformações ocorridas desde a adição da matéria orgânica fresca até à formação das frações orgânicas mais estáveis. Tal processo deu-se em duas fases: a decomposição ou biodegradação, que é um processo rápido avaliado por meio da evolução do $\mathrm{CO}_{2}$ liberado (Figura 1b), e a etapa da humificação, que envolve a formação no solo de compostos quimicamente mais estáveis do que as frações que lhe deram origem (Biryukova \& Orlov, 2004).

A qualidade da fonte de $\mathrm{C}_{\text {org }}$ alterou consideravelmente as vias de estabilizaçã̃o do $\mathrm{C}$ (Orlov et al., 2004). A adição de fontes prontamente disponíveis, como a glicose ou de exsudados solúveis, favoreceu mais a formação de huminas (Quadro 2), enquanto a adição de fontes mais estáveis (relação $\mathrm{C} / \mathrm{N}$ maior 
Quadro 2. Teores de C nas frações humificadas extaídas de um solo incubado por 90 dias com raízes de arroz coletadas aos 40, 60, 80, 100, 120 e 140 dias da semeadura (DAS)

\begin{tabular}{|c|c|c|c|c|c|c|}
\hline & AFL & AF & $\mathbf{A H}$ & $\mathbf{H}$ & AH/AF & SH \\
\hline & \multicolumn{4}{|c|}{$\mathrm{g} \mathrm{kg}^{-1}$} & & $\mathrm{~g} \mathrm{~kg} \cdot 1$ \\
\hline Solo testemunha & 0,38 & 0,17 & 0,06 & 9,78 & 0,35 & 10,39 \\
\hline Solo + glicose & 0,45 & 0,23 & 0,04 & 16,18 & 0,17 & 16,90 \\
\hline Solo + raízes - 40 DAS & 0,53 & 0,74 & 0,06 & 13,20 & 0,08 & 14,53 \\
\hline Solo + raízes - 60 DAS & 0,67 & 0,51 & 0,04 & 19,98 & 0,08 & 21,20 \\
\hline Solo + raízes - 80 DAS & 0,79 & 0,44 & 0,07 & 12,65 & 0,16 & 13,95 \\
\hline Solo + raízes - $100 \mathrm{DAS}$ & 0,69 & 0,35 & 0,06 & 11,48 & 0,17 & 12,58 \\
\hline Solo + raízes - 120 DAS & 0,70 & 0,52 & 0,06 & 11,63 & 0,12 & 12,91 \\
\hline Solo + raízes - 140 DAS & 0,53 & 0,44 & 0,06 & 11,48 & 0,14 & 12,51 \\
\hline
\end{tabular}

AFL: ácidos fúlvicos livres; AF: ácidos fúlvicos; AH: ácidos húmicos; H: huminas; AH/AF: relação entre ácidos húmicos e fúlvicos; SH: soma das frações humificadas.

que 30) favoreceu a formação de substâncias húmicas mais solúveis como os ácidos fúlvicos. Os maiores teores obtidos de $\mathrm{C}_{\text {org }}$ nos ácidos fúlvicos nas amostras de solo tratadas com raízes aos 60 e 80 DAS (Quadro 2) coincidiram com os maiores valores de C orgânico solúvel exsudado nessa fase de desenvolvimento da planta (Quadro 1), indicando ser essa fase de maior contribuição para formação de substâncias húmicas solúveis.

Os processos bioquímicos envolvidos na formação do húmus ainda não são bem entendidos. Existe, contudo, certo consenso em relação aos estádios de transformação da biomassa vegetal em húmus: (a) decomposição dos componentes da biomassa em compostos orgânicos simples, (b) metabolismo microbiano dos compostos orgânicos simples, (c) ciclagem entre a matéria orgânica do solo e a biomassa e, (d) polimerização dos compostos reciclados (Sposito, 1989). A polimerização, por meio da reunião de moléculas e exclusão de água, resulta na formação seqüencial das frações ácidos fúlvicos, ácidos húmicos e huminas (Santos \& Camargo, 1999).

No presente trabalho, foi verificado que essa seqüência dependia da fonte de $\mathrm{C}$ adicionada ao solo. Um esquema demonstrativo das vias de formação das substâncias húmicas é mostrado na figura 2 . Quanto mais prontamente assimilável, mais rápida foi a estabilização do $\mathrm{C}$ com a fração mineral na forma de huminas (Figura 2a). A formação de complexos organominerais entre polissacarídeos e oxiidróxidos de $\mathrm{Fe}$ e $\mathrm{Al}$ foi bastante estudada (Emerson et al., 1985). Se a matéria fresca adicionada apresentava maior relação $\mathrm{C} / \mathrm{N}$ ou teores mais elevados de ligninas, a fração favorecida na estabilização da matéria orgânica humificada era a dos ácidos fúlvicos (Figura 2b).

Neste trabalho, o tempo de incubação não foi suficiente para constatar as alterações na fração alcalino-solúvel mais condensada, os ácidos húmicos.
Entretanto, a qualidade do húmus do solo medida pela relação entre $\mathrm{AH}$ e $\mathrm{AF}$ foi fortemente alterada com a adição de raízes às amostras de solo

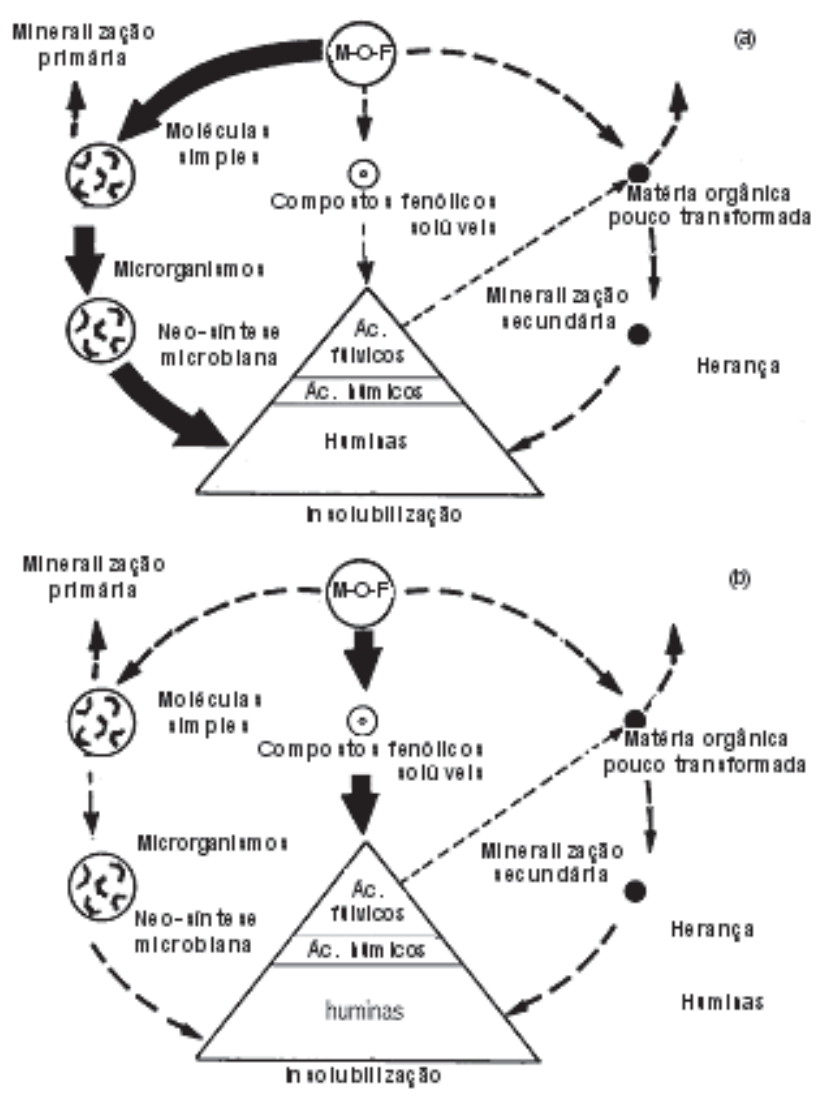

Figura 2. Esquema representativo das vias de humificação. Com adição de glicose a via de humificação favorecida é da neossíntese microbiana de compostos orgânicos rapidamente estabilizados como huminas (a); com a adição de raízes de arroz é favorecida a formação de ácidos fúlvicos por reações de policondensação (b). MOF = matéria orgânica fresca. (Adaptado de Santos, 1984). 
(Quadro 2). Os valores da relação $\mathrm{AH} / \mathrm{AF}$ diminuíram de 2 a 4 vezes nas amostras com adição de $\mathrm{C}$ mais disponível, indicando que, com a formação de um húmus de caráter mais fulvático, intensificam-se as reações do solo, uma vez que são formados compostos mais oxidados com maior acidez total.

\section{CONCLUSÕES}

1. A rizodeposição de $\mathrm{C}$ solúvel (estimada, em termos médios, em $3,8 \mathrm{~g} \mathrm{~kg}^{-1}$ de $\mathrm{C}$ nas raízes) é uma fonte importante de $\mathrm{C}$ dissolvido para o processo de humificação no solo.

2. A decomposição do sistema radicular do arroz nos diferentes estádios de desenvolvimento favoreceu a mineralização do $\mathrm{C}$ do solo.

3. O sistema radicular utilizado como fonte de matéria orgânica favoreceu o acúmulo da fração ácidos fúlvicos no solo.

4. A composição do húmus do solo foi alterada com a adição de C orgânico.

\section{LITERATURA CITADA}

BEUDERT, G.; KOGEL-KNABER, I. \& ZECH, W. Micromorphological, wet chemical and ${ }^{13} \mathrm{C}$ NMR spectroscopic characterization of density fractionated forest soils. Sci. Total Environ., 81/82:401-408, 1989.

BRONSON, K.F.; CASSMAN, R.; OLK, D.C.; VAN NOORDWIJK, M. \& GARRITY, D.P. Soil carbon dynamics in different cropping systems in principal ecoregions of Asia. In: LAL, R.; KIMBLE, J. \& FOLLETT, R., eds. Boca Raton, Management of Carbon Sequestration in Soil, CRC Press, 1998, p.35-57.

CAMARGO, F.A.O.; SANTOS, G.A. \& GUERRA, J.G. Macromoléculas e substâncias húmicas. In: SANTOS, G.A. \& CAMARGO, F.A.O., eds. Fundamentos da matéria orgânica: ecossistemas tropicais e subtropicais. Porto Alegre, Gênesis, 1999. p.27-40.

CONTE, P. \& PICCOLO, A. Conformational arrangement of dissolved humic substances. Influence of solution composition on association of humic molecules. Environ. Sci. Technol., 32:1682-1690, 1999.

EMERSON, W.W.; FOSTER, R.C. \& OADES, J.M. OrganoMineral complexes in relation to soil aggregation and structure. In: HUANG, P.M. \& SCHNITZER, M., eds. Interactions of soil minerals with natural organics and microbes. Madison, Soil Science Society of America, 1985. p.521-548. (Special Publications Number, 17)
ENGEBRETSON, R.R. \& von WANDRUSZKA, R. Microorganization in dissolved humic acids. Environ. Sci. Technol., 28:1934-1941, 1994.

FAÇANHA, A.R.; FAÇANHA, A.; OLIVARES, F.L.; GURIDI, F.; SANTOS, G.A.; VELLOSO, A.C.X.; RUMJANEK, V.M.; BRASIL, F.; SCHRISPEMA, J.; BRAZ-FILHO, R.; OLIVEIRA, M.A. \& CANELLAS, L.P. Bioatividade de ácidos húmicos: Efeitos sobre o desenvolvimento radicular e sobre a bomba de prótons da membrana plasmática. Pesq. Agropec. Bras., 37:1301-1310, 2002.

FURLANI, A.M.C. \& FURLANI, J.L. Composição e pH de soluções nutritivas para estudos fisiológicos e seleção de plantas em condições nutricionais diversas. Campinas, Instituto Agronômico de Campinas, 1988. (Boletim Técnico, 121)

GERZABEK, M.H.; PICHLMAYER, F.; KIRCHMANN, H. \& HABERHAUER, G. The response of soil organic matter to manure amendments in a log-term experiment at ULTUNA, SWEDEN. Eur. J. Soil Sci., 48:273-282, 1997.

GILL, A.M. \& JACSON, R.B. Global pattern of root turnover for terrestrial ecosystems. New Phytol., 147:13-31, 2000.

GUERRA, J.G. \& SANTOS, G.A. Métodos químicos e físicos. In: SANTOS, G.A. \& CAMARGO, F.A.O., eds. Fundamentos da matéria orgânica: Ecossistemas tropicais e subtropicais. Porto Alegre, Gênesis, 1999. p.267-292.

KOGEL-KNABER, I. The macromolecular organic composition of plant and microbial residues as inputs to soil organic matter. Soil Biol. Biochem., 34:139-162, 2002.

KUZYAKOV, Y.; STAHR, J.K. \& FRIEDEL, K. Review of mechanisms and quantifcation of priming effects. Soil Biol. Biochem., 32:1485-1498, 2000.

KUZYALOV, Y. \& DOMANSKI, G. Carbon input by plants into soil. Rev. J. Plant Nutr. Soil Sci., 163:421-431, 2000.

LUNA-GUIDO, M.L.; BELTRAÂN-HERNAÂNDEZ, R.I. \& DENDOOVEN L. Dynamics of ${ }^{14}$ C-labelled glucose in alkaline saline soil. Soil Biol. Biochem. 33:707-719, 2001.

OLIVEIRA, A.M.G. Evolução da matéria orgânica, modificações no $\mathrm{pH}$ e alumínio trocável a partir da adição de substratos orgânicos e calcário em um Latossolo. Seropédica, Universidade Federal do Rio de Janeiro, 1990. 121p. (Tese de Mestrado)

ORLOV, D.S.; BIRYUKOVA, O.N. \& ROZANOVA, M.S. Revised system of the humus status parameters of soils and their genetic horizons. Eur. Soil Sci., 37:798-805, 2004.

ORTEGA, F. La matéria orgánica de los suelos y el humus de los suelos de Cuba. La Habana, Academia de Ciéncias de Cuba, 1982. 126p.

PRESTON, C. The application of NMR to organic matter inputs and process in forest ecosystems of the Pacific nortthwest. Sci. Total Environ., 113:107-120, 1992.

RAICH J.W. \& NADELHOFFER, K.J. Belowground carbon allocation in forest ecosystemas: global trends. Ecology, 70:1346-1354, 1989. 
SANTOS, G.A. Contribution a l'étude des interactions matière organique et phosphore dans un sol ferralitique. Nancy, Institut National Polytechnique de Lorraine, 1984.148p. (Tese de Doutorado)

SPOSITO, G. The chemistry of soils. New York, Oxford Academic Press, 1989. 227p.

SWIFT, R.S. Macromolecular properties of soil humic substances: fact, fiction and opinion. Soil Sci. 164:790-802, 1999.

VOGT, K.A.; GRIER, C.C. \& VOGT, D.J. Production, turnover and nutrient dynamics of above and belowground detritus of world forest. Adv. Ecol. Res., 15:303-377, 1986.
WALKLEY, A.A. A critical examination of a rapid method for determining organic carbon in soils - Effec of variations in digestion conditions and of inorganic soil constituents. Soil Sci., 97:34-42, 1947.

WERSHAW, R.L. Model for humus in soils and sediments. Environ. Sci. Technol., 27:814-816, 1993.

ZECH, W.; SENESI, N.; GUGGENBERGER, G.; KAISER, K.; LEHMANN, J.; MIANO, T.M.; MILTNER, A. \& SCHROTH, G. Factors controlling humification and mineralization of soil organic matter in the tropics. Geoderma, 79:117-161, 1997. 